\title{
CrimRxiv
}

\section{Stigma and Mental Health of Sexual Minority Women Former Victims of Intimate Partner Violence}

Emma Fedele, Robert-Paul Juster, Stephane Guay

Published on: Feb 23, 2022

DOI: $10.21428 / \mathrm{cb} 6 \mathrm{ab} 371.8 \mathrm{a} 87 \mathrm{a} 8 \mathrm{ee}$

License: Creative Commons Attribution 4.0 International License (CC-BY 4.0). 
